Although the celebrations were to mark the jubilee of the electron, everyone who listened to the lectures or sees the Exhibition is bound to be impressed by the still great youthfulness and vigour of the electron, for the potentialities of the new science of electronics are attracting to their study and exploitation such an amount of skill and enterprise that what has been accomplished can be regarded only as a beginning of the achievements of the liberated electron.

\section{S. WeInTroub}

\section{INTERNATIONAL STANDARDS AND UNITS OF RADIOACTIVITY}

$\mathrm{T}$

HE first international radium standard was prepared by Mme. Curie in 1911; it consisted of $21.99 \mathrm{mgm}$. of purest radium chloride. By comparing its radiation with those from other radium sources, the latter could be measured and their radium contents expressed in grams. For the measurement of radon, grams (or cubic centimetres) of this gas are impracticable as units, and it was therefore decided to use as unit of radon the quantity which is in radioactive equilibrium with $1 \mathrm{gm}$. of radium; it was called a 'curie'. Standards for radon measurements were prepared in the form of solutions of radium salts.

Since the comparison of radioactive sources with the standards always involved measurements of ionization currents, or of the number of disintegrations per unit of time, and as especially the latter figure could be determined with much higher accuracy than the weight of the radium preparation, it became customary to base the eurie directly on the number of alpha-particles emitted. According to the best measurements, $1 \mathrm{gm}$. of radium and, naturally, also the radon in equilibrium with this quantity, emits per second $3.7^{\circ} \times 10^{10}$ alpha-particles; in recent practice, unknown radioactive sources were measured in curies by comparing their particle emission with this figure. Thus the curie became the unit in which the strength not only of members of the radium family, but also of any radioactive source, could be expressed.

This important change in the principle of radioactive measurements and in the definition of the curie was never officially sanctioned, because the International Radium Standard Commission which was responsible for the early conventions on radioactive standards and units has for a long time not been able to function satisfactorily. To remedy this situation, the proposal was made bv E. U. Condon and L. F. Curtiss (Rev. Sci. Instr., 17, 249 ; 1946) to introduce as a new unit the activity of $10^{6}$ disintegrations per second, and to call it a 'rutherford'.

It is obvious that an international agreement is imperative, whether the 'curie' in its original or in its modified form, or the new unit, the 'rutherford', should be used. The International Congress of Chemistry recently held in London offered to a number of workers in radioactivity from various countries an opportunity to discuss this question among themselves. Under the chairmanship of Prof. F. JoliotCurie (Paris), on July 19, a meeting was held by Ellen Gleditsch (Oslo), G. de Hevesy (Stockholm), Irene Joliot-Curie (Paris), C. Jacobsen (Copenhagen), W. A. Noyes, jun. (Rochester), F. A. Paneth (Durham) and G. J. Sizoo (Amsterdam) ; and after an exchange of views they decided to make the following recommendation.
A new committee on radioactive standards and units, comprising mainly representatives of the International Union of Chemistry and of the International Union of Physics, should be formed; but all the surviving members of the old International Radium Standard Commission should be invited to join them. As representatives of the International Union of Chemistry the names of E. Gleditsch, G. de Hevesy, Warren C. Johnson, F. Joliot-Curie, F. A. Paneth and G. T. Seaborg were suggested; as repre. sentatives of the International Union of Physics those of L. F. Curtiss, Sir Charles Darwin, R. B. Evans, C. Jacobsen, Irene Joliot-Curie and G. J. Sizoo.

Those present at the meeting were unanimously in. favour of preserving the name of 'curie' as the unit of radioactivity, but to define it now officially as the quantity of a radio-element which undergoes $3.700 \times$ $10^{10}$ radioactive transformations per second. The final decision, however, will have to await the recommendations of an international committee on radioactive standards, the formation of which was advocated.

\section{QUANTITATIVE ASPECTS OF FREE RADICAL CHEMISTRY}

\author{
By Prof. H. W. MELVILLE, F.R.S. \\ University of Aberdeen
}

$T$ HE Faraday Society held a two-day meoting in Oxford during September 23-25 to discuss "The Labile Molecule", or the quantitative aspects of free radical chemistry. The nature of the discussion seemed commonplace enough, and the tremendous activity in this field of chemistry is almost taken for granted. If we neglect the war years-and that is not quite justified - the subject seems to have grown up in about five scientific years, from a rather tentative qualitative notion to a subject of considerable precision requiring for its practice a wide variety of advanced techniques.

The attempts to unravel the mechanism of chemical reactions, the mechanism of which does not involve ions, is really the story of the development of the kinetics of homogeneous reactions. Many reactions, and especially those involving halogens, are known to involve free atoms as essential intermediates. These are, in fact, the activated 'molecules' in the old Arrhenius sense. But the idea that free organic radicals could function in a similar way, though possible in principle, came at a much later stage. The preparation of simple aliphatic radicals by the thermal decomposition of metallic alkyls, and later of a large number of simple organic molecules, provided the idea that radicals might play a part in the thermal decomposition of molecules the spontaneous decomposition of which was regarded as occurring simply by fission into simpler molecules but not radicals. Similarly, a great deal of work on the photochemical decomposition of compounds like the simpler aliphatic ketones could only be satisfactorily explained if it were assumed that the first step in the reaction consisted in the fission of a carbon - carbon bond with the production of two free radicals. Such experiments, however, gave little quantitative information about the reactivity of the radicals pro. duced, for the simple reason that the radicals mostly recombined, and therefore the velocity of decomposition was fixed by the initial rate of decomposition 